SCIREA Journal of Chemistry

http://www.scirea.org/journal/Chemistry

November 1, 2021

Volume 6, Issue 2, April 2021

\title{
Phase Transitions and the Phase Diagrams
}

\author{
Beycan İbrahimoglu', Beycan İbrahimoglu Jr. ${ }^{2}$, Eda Bolayır ${ }^{2}$ \\ ${ }^{1}$ Industrial Engineering, Ankara Science University, Ankara, Turkey \\ ${ }^{2}$ Anadolu Plasma Technology Center, Ankara, Turkey \\ *In all publications before 1993, the main author's name is Beycan Farzaliyev
}

\begin{abstract}
A phase diagram is a graphical representation of the physical states of a substance under different pressure and temperature conditions based on experimental data. Generally, pressure-temperature $(\mathrm{p}-\mathrm{T})$ diagrams under constant volume $(\mathrm{V})$ are preferred for simplicity and easy understanding. The positions of solid, liquid and gas phases, equilibrium lines between phases, the triple point where these lines intersect $(\operatorname{trp})$ and the critical point $\left(\mathrm{T}_{\mathrm{cr}}, \mathrm{P}_{\mathrm{cr}}\right.$, $\left.\rho_{\mathrm{cr}}\right)$ where the liquid-gas equilibrium line ends are located in the $\mathrm{p}$ - $\mathrm{T}$ diagram of onecomponent substances. The positions of the triple point and the critical point vary depending on the material taken. In contrast, conventional phase diagrams do not have a position showing the plasma phase, which makes up $95-98 \%$ of the universe. In other words, the boundary lines between solid, liquid and gas phases and plasma are not determined. In addition, the ending position of the solid-liquid equilibrium curve, whose beginning is known at the triple point, and the uncertainty of the liquid phase continue.

In this study, the metastable state of benzene at high pressure and temperature was examined and a critical pressure point $\left(\mathrm{p}_{\mathrm{cr}}\right)$ was determined on the melting equilibrium curve. In addition, with the application of the thermodynamic geometry system and the evaluation of the axiomatic method, the melting equilibrium curves of many organic and inorganic substances
\end{abstract}


ending with a critical point has been shown. Location of plasma in single component system $\mathrm{p}-\mathrm{T}$ phase diagram determined and modeled considering benzene atom.

Keywords: Critical temperature, critical pressure, liquid phase, axiogeometry, benzene

\section{Introduction}

The phase diagram is a graphical representation of the relationship between the state parameters of a thermodynamic system at equilibrium. The main features of a phase diagram are phase boundaries and triple point. The phase diagram can be considered as a "land plan", which greatly facilitates the perception of the picture of the structure of the heterogeneous system as a whole. Such diagrams are widely used in metallurgy, materials science, geochemistry, analysis of solidification processes, chemical technology, crystal growth, welding, analysis of reactions. The conventional one-component $\mathrm{p}-\mathrm{T}$ phase diagram is given in Figure 1.

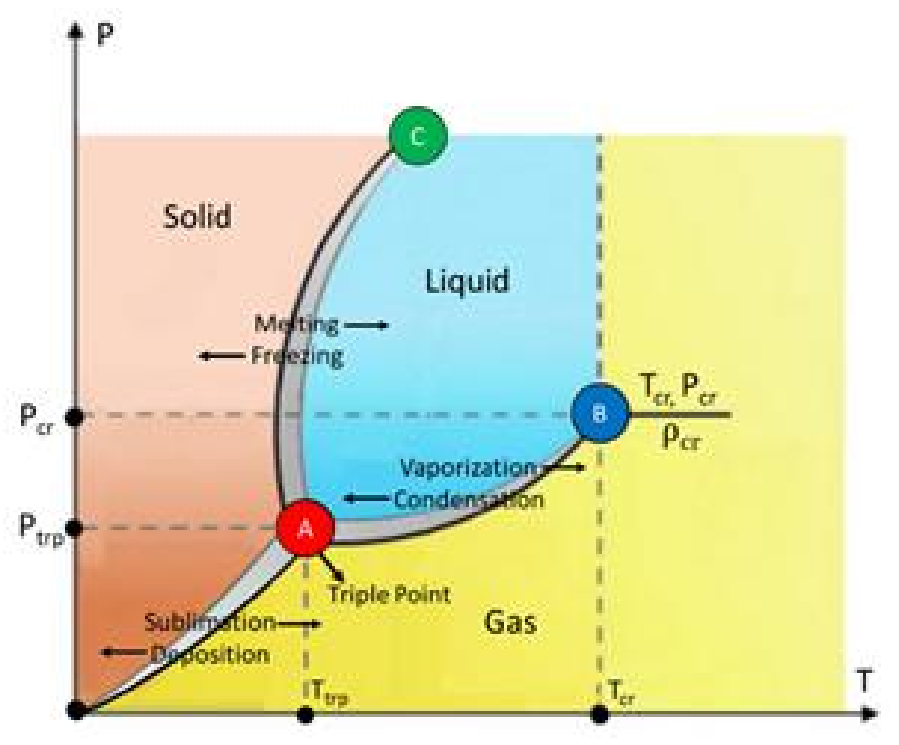

Figure 1. Conventional one-component p-T phase diagram

In this diagram, the existence of the $C$ point where the liquid-solid equilibrium curve ends and the uncertainty of the boundary gap of the liquid phase continue. At point B, where the liquidgas equilibrium curve ends, only the temperature $T_{c r}$ is critical. $P_{c r}$ and $\rho_{c r}$ in the diagram are the pressure and density corresponding to the temperature at point $\mathrm{B}$ and are not critical. This led to the development of a new P-T diagram representing single component systems to determine critical pressure $p_{c r}$, critical $\rho_{c r}$ density and plasma. In accordance with the phase 
rule proposed by Gibbs in 1876, the development of the phase diagram, which includes the four aggregate states of pure substances, is in question. For this purpose, the boundary range of the liquid phase and the critical point where the liquid-gas equilibrium curve ends were investigated.

\section{Liquid Phase of the Substance}

Liquid phase; It is located in a very wide temperature range between the solid and gas phases. It has constant volume and density at a given temperature. Molecules in contact with each other in the liquid are constantly in translation, rotation and vibration motion. Accordingly, the kinetic energy of the molecules in the liquid phase is higher than those in the solid phase, which can only vibrate. Although detailed studies have been carried out on it, it cannot be said that how it changes depending on the pressure and temperature applied on its location and existence time has not been examined in detail. The boundaries of the liquid phase are indicated by dots indicating temperature and pressure. The position where the liquid has completely disappeared is called the "critical point".

\section{Temperature Range of The Liquid Phase}

As can be seen in Figure 2, the temperature range of the liquid phase lies between the triple point temperature $\left(\mathrm{T}_{\mathrm{tp}}\right)$ and the critical point temperature $\left(\mathrm{T}_{\mathrm{cr}}\right)$ on the $\mathrm{T}$-axis. The liquid phase heated from the triple point ends at the critical point. Conversely, the liquid cooled from the critical point terminates at the triple point. Depending on the temperature, the liquid phase exists only between two fundamental points $\left(\mathrm{T}_{\mathrm{tp}}\right.$ and $\left.\mathrm{T}_{\mathrm{cr}}\right)$.

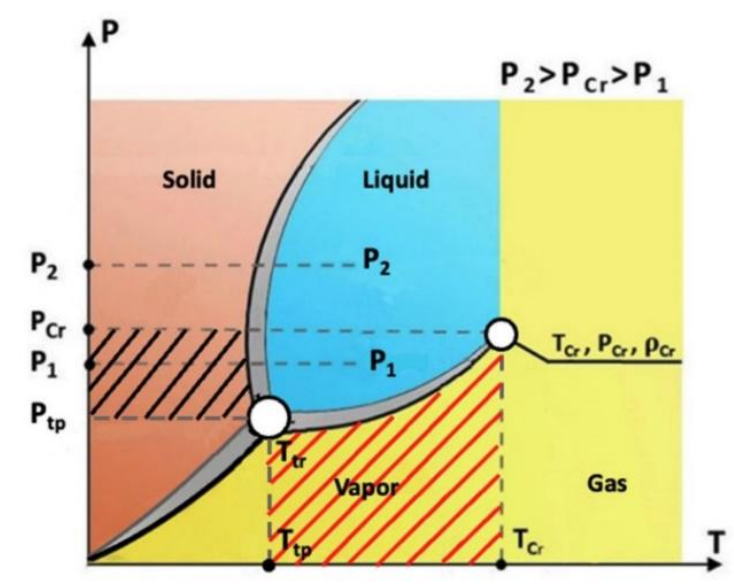

Figure 2. Critical parameters shown on p-T phase diagram 


\section{Pressure Range of The Liquid Phase}

Pressure is one of the state variables that have an effect on the liquid phase. It is seen in Figure 2 that the pressure range of the liquid phase lies between the triple point pressure $\left(\mathrm{P}_{\mathrm{tp}}\right)$ and the critical point pressure $\left(\mathrm{P}_{\mathrm{cr}}\right)$ on the $\mathrm{P}$-axis. As indicated in the figure, there are different constant pressures $\mathrm{p}_{1}, \mathrm{p}_{2}$ in the liquid phase. Of these, $\mathrm{p}_{1}$ is below the critical pressure and $\mathrm{p}_{2}$ is in the liquid phase above the critical pressure. It is seen that the critical pressure is between $\mathrm{p}_{1}$ and $\mathrm{p}_{2}$ pressures in the liquid phase at different values. Similarly, $\mathrm{p}_{1}<\mathrm{p}_{\mathrm{cr}}$ and $\mathrm{p}_{2}>\mathrm{p}_{\mathrm{cr}}$ analogs are not likely to be critical for the liquid phase. In summary, it can be said that the only characteristic parameter for the critical point is the critical temperature $T_{\text {cr. }}$ In this case, an actual critical pressure of the liquid phase needs to be investigated experimentally.

Looking at Figure 2, the temperature $\mathrm{T}_{\mathrm{cr}}$ perpendicular to the temperature axis is constant and does not change with pressure. Conversely, the positions in which the liquid exists do not change with temperature along lines perpendicular to the pressure and density $\rho-p$ axis. Accordingly, it is not known exactly at what pressure the liquid phase starts pressure and ends from the triple point. In other words, it does not show the pressure range of the liquid phase between $p_{t p}$ and $p_{c r}$. The critical pressure and critical density in conventional phase diagrams are only the pressure and density corresponding to the critical temperature. They cannot represent a critical situation.

The question of whether there is a point representing the critical pressure $p_{c r}$ in a onecomponent system is being discussed.

In our opinion, it is possible to determine the presence and position of the actual critical pressure pcr in a one-component system with axiogeometry and experimental methods.

\section{Determination of the Actual Critical Pressure $p_{c r}$}

Axiogeometry; describes a general statement (usually in graphical form) based on experience, observation of some aspect of the physical world, and will include the relationship between various quantities under certain conditions. For example, it graphically defines the relationship between the volume, pressure and temperature of a fixed mass of a gas (V-T, $\mathrm{p}=$ constant). This chart is just a description of an existing situation. Graphs are a way of describing scientific observations or experiments. The acceptance of absolute temperature as graphically determined by Kelvin is a graphical representation of inferences drawn from 
careful measurements and observations made by Gay-Lussac and other scientists.Kelvin applied graphical method to $\mathrm{p}-\mathrm{T}, \mathrm{V}=$ constant and $\mathrm{V}-\mathrm{T}, \mathrm{p}=$ constant diagrams of the gas phase of substances, and the absolute temperature of substances in the solid phase was determined as $\mathrm{T}(\mathrm{K})=\mathrm{t}(\mathrm{C})+273.15{ }^{\circ} \mathrm{C}$ with great accuracy. Even today, despite the technological developments, Kelvin's V $=0, \mathrm{~T}=-273.15^{\circ} \mathrm{C}$ absolute temperature for solids has not yet been reached experimentally. According to observations provided in the gas and liquid phases of hydrogen behave completely different [1-3].

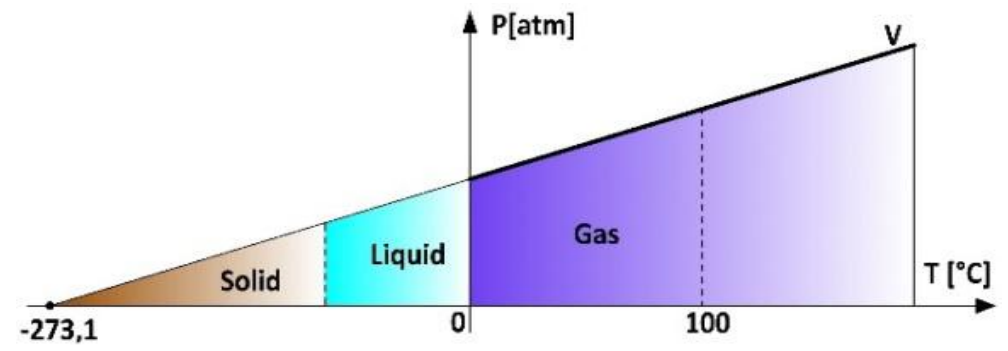

Figure 3. Determination of absolute temperature in $\mathrm{p}-\mathrm{T}, \mathrm{V}=$ constant diagram

Kelvin's method has started from the following postulates that are later accepted as the postulates of the ideal gas law:

i. $\quad\left(\frac{\partial V}{\partial T}\right)_{P}=$ constant

ii. There is a unique temperature where $\mathrm{V}=0$ for all substances, at all pressures.

Same method used to determine the temperature of ionization and decomposition of the substance, using the $\rho-P, T=$ constant dependence on the gas phase of the substance and the graph obtained given in Figure 2 [4-10].

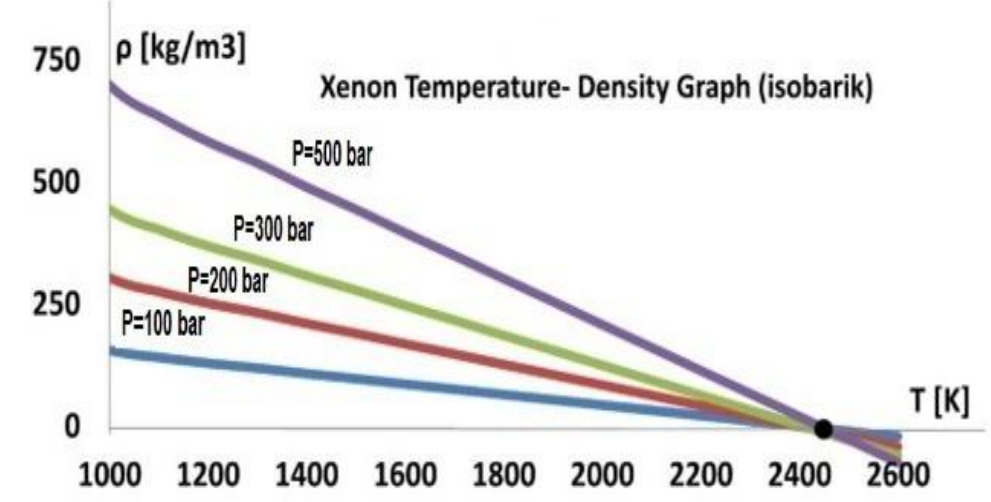

Figure 4. Determination of ionization temperature in the $\rho-p, T=$ constant diagram 
Studies revealed that the $\rho-p, T=$ constant dependence shows the ionization point in monatomic gases and the decomposition temperature in polyatomic gases.

It is possible to apply this method, which is applied to the gas phase of the substances, to the solid and liquid phase of the substances.

\section{Application of Geometric Method to Liquid Phase of Substances}

Density and viscosity tests of benzonitrile, ortho-, meta-, para-toluidines at high pressure and temperature were carried out [11-14] and $\mathrm{T}=$ constant dependency was applied to the obtained test results $(\rho-\mathrm{P})$. As an example, the experimental results of benzonitrile at high pressure and temperature are shown in Figure 5 in $(\rho-P), T=$ constant diagram.

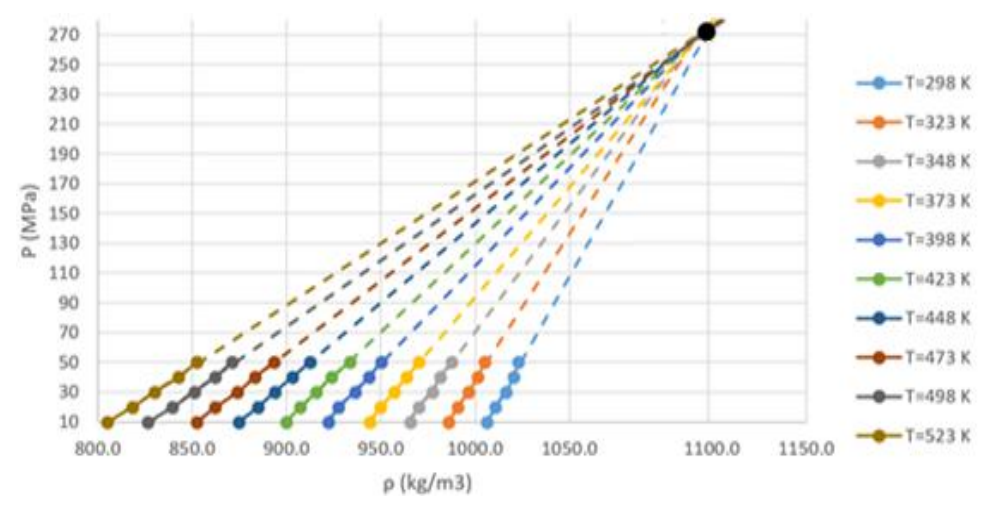

Figure 5. Point where the isotherms of benzonitrile, at $p-\rho, T=$ constant dependency, intersect on the

$$
p \text { axis }\left(p=270 \mathrm{MPa} \text { and density } \rho=1100 \mathrm{~kg} / \mathrm{m}^{3}\right)
$$

When the graphical method was applied to $p-\rho, T=$ constant diagram, it was observed that at high pressure, the isotherms merge into a point for liquid phase of hydrocarbons. For example, $\mathrm{p}-\rho, \mathrm{T}=$ constant dependencies were applied to the liquid phase of benzonitrile at high pressure and temperature. It was observed that in the liquid phase of benzonitrile, isotherms intersect at an unknown point shown in Figure 5 and this point is considered as the real critical pressure.

i. $\quad\left(\frac{\partial \rho}{\partial P}\right)_{T}=$ constant

ii. There exists a pressure where density of the fluid is zero for all temperatures.

iii. Also, Figure 5 is the logical expression of Figures 3 and 4. 
True critical pressure and critical density values for benzonitrile and some other hydrocarbons are presented in Table 1.

Table 2. Solid-liquid critical pressure value of some hydrocarbons

\begin{tabular}{|c|c|c|c|}
\hline Matter & Chemical Formula & Critical Pressure [Mpa] & Density [kg/m $\left.\mathbf{m}^{\mathbf{3}}\right]$ \\
\hline n-Decane & $\mathrm{C}_{10} \mathrm{H}_{12}$ & 130 & 839 \\
\hline n-Nonan & $\mathrm{C}_{9} \mathrm{H}_{20}$ & 150 & 826 \\
\hline n-Xylene & $\mathrm{C}_{8} \mathrm{H}_{10}$ & 200 & 990 \\
\hline o-Xylene & $\mathrm{C}_{8} \mathrm{H}_{10}$ & 205 & 1000 \\
\hline o-Toluidine & $\mathrm{C}_{7} \mathrm{H}_{9} \mathrm{~N}$ & 150 & 1400 \\
\hline m-Toluidine & $\mathrm{C}_{7} \mathrm{H}_{9} \mathrm{~N}$ & 140 & 1450 \\
\hline p-Toluidine & $\mathrm{C}_{7} \mathrm{H}_{9} \mathrm{~N}$ & 200 & 1100 \\
\hline Benzonitrile & $\mathrm{C}_{7} \mathrm{H}_{5} \mathrm{~N}$ & 185 & 1350 \\
\hline Benzene & $\mathrm{C}_{6} \mathrm{H}_{6}$ & 210 & 1200 \\
\hline
\end{tabular}

\section{Benzene Critical Point Found on Melting Equilibrium Curve Using Experimental Method}

The existence of a fundamental point on the liquid-solid equilibrium curves of benzene and other organic and inorganic substances should be determined experimentally by axiogeometric method. For this purpose, it was foreseen to determine the basic point by examining the metastable state of benzene at high pressure and temperature. By the way, a large number of metastable phases have been studied mostly on the evaporation equilibrium curves [11-16].

P.W. Bridgman, inspired by the critical point at the end of the liquid-vapor equilibrium curve, investigated the existence of a critical point that marks the end of the liquid-solid equilibrium curve. For this purpose, he investigated the existence of a fundamental point with zero volume change $(\Delta \mathrm{V})$, enthalpy change $(\Delta \mathrm{H})$ and entropy change $(\Delta \mathrm{S})$ in the liquid-solid equilibrium curve at high pressures and temperatures. Since he could not determine that these quantities were zero, he argued that a critical point could not be found on the liquid-solid equilibrium curve. In fact, the increases in the chemical potentials of the phases with the effect of increase in external pressure during the phase transition prevent the simultaneous elimination of the 
$\Delta \mathrm{V}$ and $\Delta \mathrm{S}$ changes. During these studies, there was no agreement on the existence of a critical point where the liquid-solid equilibrium curve terminates.

According to the Paul Ehrenfest classification, transitions in which the thermodynamic potential $(\mu)$ is continuous but the partial derivatives of $(\partial \mu / \partial \mathrm{T})_{\mathrm{P}}=-\mathrm{S}$ and $(\partial \mu / \partial \mathrm{p})_{\mathrm{T}}=\mathrm{V}$ are discontinuous are called first-order phase transitions. The liquid-solid transition, in which the metastable state occurs, is also of the first order. In order to determine the critical point where the freezing-melting equilibrium line ends, it is envisaged to examine the change of the metastable state with increasing pressure. As the externally applied pressure increases, the duration of the metastable state seeps away. Accordingly, the pressure and temperature at which the duration of the metastable state is reset are the subjects of the endpoint of the freezing-melting line. Thus, we decided to examine benzene at high pressures and temperatures in experiments. However, in our experiments, the metastable state of benzene was investigated.

\section{Metastable State}

The metastable state is produced on the liquid-vapor, liquid-solid and solid-steam equilibrium curves at the triple point, with the effect of external parameters such as pressure and temperature, and ends in the equilibrium curves when the metastable state is reset. Phase transitions are classified according to the metastable phase [17]. The first type of "discrete metastable state" was used in our experiments.

\section{Experiment Setup and Technique}

With the help of the experimental facility provided $[5,9,16]$, we measured and controlled the following parameters of the benzene meta-stable state: pressure $p$, container temperature, freezing temperature $T_{b}$ (i.e. crystallization temperature), temperature $T_{c}$ in the low point of the meta-stable state, overcooling $\Delta T^{-}=T_{b}-T_{c}$ relative to freezing temperature, pressure difference $\Delta p$ at the initial stage of explosive crystallization, incubation period $t_{1}$ of liquid benzene stay in the meta-stable (overcooled) state, $t_{2}$ - the time of an abrupt transition from 
the meta-stable state to the crystalline one, $t_{3}$ - the time of isothermal freezing, the total time $t$ of solidification $\left(t=t_{1}+t_{2}+t_{3}\right)$.

\section{Experimental Results}

Two schematic thermo-grams of benzene cooling (Figure 6) with (I) and without (II) a metastable area of benzene of volume $10 \mathrm{~cm}^{3}$ at 0.1 atm were analyzed.

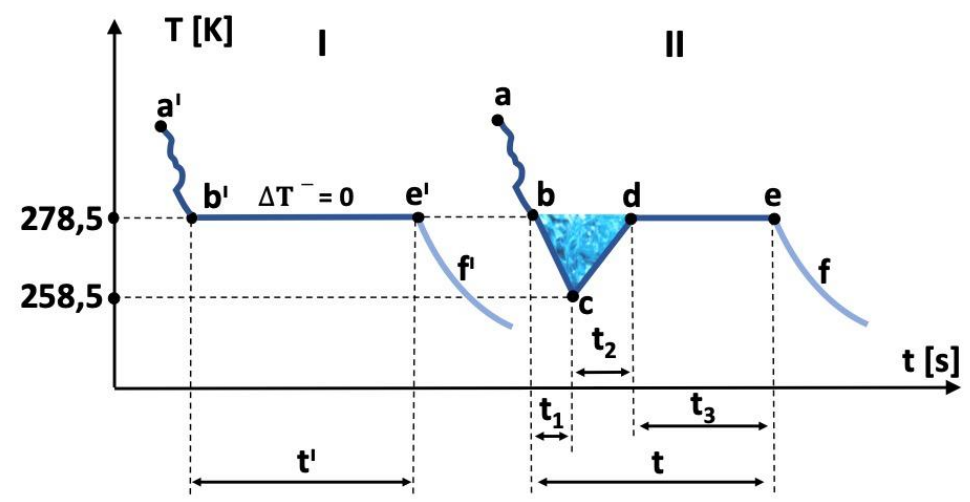

Figure 6. Schematic thermo-grams in the $T-t$ coordinates recorded at $p=1 \mathrm{~atm}$. They characterise

(I) the absence of a meta-stable state and equilibrium crystallization and (II) the availability of a meta-stable state and non-equilibrium-explosive crystallization.

The first thermogram characterizes an overcooling-free equilibrium crystallization ( $\Delta T^{-} \approx 0$ ). Such thermograms are fixed after a small pre-heating of liquid benzene and its cooling [39]. On the way $a^{\prime} \rightarrow b$ a liquid phase cools down and on the way $b \rightarrow e^{\prime}$ the isothemal crystallization takes place at $278.5 \mathrm{~K}$, this temperature coincides with benzene melting temperature $T_{L}$ [40]. On the way $e^{\prime} \rightarrow f$ solid benzene cools down. Point $b$ on the thermogram is conventionally called one of the boundaries of the metastable state at the minimum overcooling $\Delta T^{-}=0$. In benzene cooling from higher temperature (with an overheating of about $\Delta T^{+}>5 \mathrm{~K}$ relative to $T_{L}$ ), i.e. from point $a>a^{\prime}$ on thermogram II, another shape of the $T-t$ curve is observed. Temperature approaches to the area of overcooled state along the way $b \rightarrow e$. Assume that point $c$ is the lower boundary of meta-stable state of liquid benzene and it corresponds to some temperature $T_{c}=258.5 \mathrm{~K}$ (i.e. to overcooling $\left.\Delta T^{-}=20 \mathrm{~K}\right)$. Time $t_{1} \approx 160 \mathrm{~s}$ is an incubation period of the liquid phase stay in the metastable state. In a time $t_{1}$ on the boundary of metastability, temperature starts rising quickly 
from point $c$ to point $d$ for a time $t_{2} \approx 6 \mathrm{~s}$. As this takes place, the rate of adiabatic process on the segment $c d$ is $\sim 4 \mathrm{~K} / \mathrm{s}$. Keeping in mind that the system cooling rate is $\sim 0.14 \mathrm{~K} / \mathrm{c}<<4 \mathrm{~K} / \mathrm{s}$, heat losses into the environment can be neglected and the equation of heat balance can be written as $Q_{1} \approx Q_{2}$, i.e. $m_{x} \Delta H_{L S} \approx c_{p} m \Delta T^{-}$, where $m_{x}$ is the mass of a solidified part of the sample after the termination of meta-stable state, $m=8.8 \mathrm{~g}$ is the mass of the whole sample of benzene, $c_{p}=1759 \frac{\mathrm{J}}{\mathrm{mole} \cdot \mathrm{K}}$ is specific heat capacity, $\Delta H_{L S}=128 \frac{\mathrm{kJ}}{\mathrm{kg}}$ is enthalpy of benzene melting [9]. From this formula one cam calculate an initial fraction of volume (or mass) of the solidified benzene after its stay in the meta-stable state: $\alpha=\frac{m_{x}}{m}=\frac{c_{p} \Delta T^{-}}{\Delta H_{L S}}=0.27$. That is $m_{x} \approx 2.4 \mathrm{~g}$. Then, on thermogram II the remaining part of benzene $\beta=1-\alpha=0,73$ freezes in a time $t_{2}=260 \mathrm{~s}$ (or $6.4 \mathrm{~g}$ ) at temperature $278.5 \mathrm{~K}$. Thus the total time $t$ of the whole process of solidification was $\sim 426 \mathrm{~s}$. On the thermograms the relative concetration $\eta$ of all crystal-like clusters in a meta-stable liquid phase was calculated from the formula $\eta=\frac{\tau_{1}}{\tau}$ [34], in practice this concetration was in the range of $0.37 \pm 1$ at all pressures.

The thermograms like thermogram II in Figure 7 were also obtained at other static pressures $p$ up to $2300 \mathrm{~atm}$. In Table 3 the average values of singular points at 24 different pressures were provided. In this table there are also given temperatures $T_{b}, T_{c}, T_{d}, T_{e}$ corresponding to points $b, c, d, e$ on the thermograms, pressures $p_{c}$ and $p_{d}$ in points $c$ and $d$, pressure differences $\Delta p$ at a temperature transition from point $c$ up to point $d$ and time intervals $t_{1}, t_{2}$, $t_{3}, t$

Table 3. Parameters of the metastable state of benzene and its freezing on the thermograms

\begin{tabular}{|c|c|c|c|c|c|c|c|c|c|c|c|}
\hline $\begin{array}{c}p, \\
\mathbf{a t m}\end{array}$ & $\begin{array}{c}\boldsymbol{T}_{\boldsymbol{b}}, \\
\mathbf{K}\end{array}$ & $\begin{array}{c}\boldsymbol{T}_{\boldsymbol{c}}, \\
\mathbf{K}\end{array}$ & $\begin{array}{c}\Delta T_{\mathbf{K}}^{-}, \\
\mathbf{K}\end{array}$ & $\begin{array}{c}\boldsymbol{T}_{\boldsymbol{d}}=\boldsymbol{T}_{\boldsymbol{e}}, \\
\mathbf{K}\end{array}$ & $\begin{array}{c}\boldsymbol{p}_{\boldsymbol{c}}, \\
\mathbf{a t m}\end{array}$ & $\begin{array}{c}\boldsymbol{p}_{\boldsymbol{d}}, \\
\mathbf{a t m}\end{array}$ & $\begin{array}{c}\Delta p, \\
\mathbf{a t m}\end{array}$ & $\begin{array}{c}\boldsymbol{t}_{\mathbf{1}}, \\
\mathbf{S}\end{array}$ & $\begin{array}{c}\boldsymbol{t}_{\mathbf{2}}, \\
\mathbf{s}\end{array}$ & $\begin{array}{c}\boldsymbol{t}_{\mathbf{3}}, \\
\mathbf{S}\end{array}$ & $\begin{array}{c}\boldsymbol{t}, \\
\mathbf{s}\end{array}$ \\
\hline 0.1 & 278.5 & 258.5 & 20.0 & 278.5 & - & - & - & 160 & $\sim 6.0$ & 260 & 426 \\
\hline 100 & 279.0 & 267.0 & 13.0 & 279.0 & 100 & 68 & 32.0 & 131 & $\sim 3.0$ & 210 & 343 \\
\hline 200 & 280.0 & 270.0 & 10.0 & 280.0 & 200 & 173 & 27.0 & 112 & $\sim 2.5$ & 180 & 294 \\
\hline 300 & 282.8 & 274.6 & 8.2 & 282.8 & 300 & 277 & 23.0 & 97 & $\sim 2.0$ & 155 & 254 \\
\hline
\end{tabular}




\begin{tabular}{|c|c|c|c|c|c|c|c|c|c|c|c|}
\hline 400 & 284.8 & 277.8 & 7.0 & 284.8 & 400 & 380 & 20.0 & 85 & $\sim 2.0$ & 135 & 222 \\
\hline 500 & 286.7 & 280.7 & 6.0 & 286.7 & 500 & 482.5 & 17.5 & 72 & $\sim 2.0$ & 115 & 189 \\
\hline 600 & 289.5 & 284.5 & 5.0 & 289.5 & 600 & 585 & 15.0 & 61 & $\sim 1.5$ & 97 & 159 \\
\hline 700 & 291.2 & 287.2 & 4.0 & 291.2 & 700 & 687 & 13.0 & 53 & $\sim 1.5$ & 85 & 139 \\
\hline 800 & 294.8 & 291.2 & 3.6 & 294.8 & 800 & 788.5 & 11.5 & 44 & $\sim 1.5$ & 70 & 115 \\
\hline 900 & 297.0 & 293.8 & 3.3 & 297.0 & 900 & 890.5 & 9.5 & 37 & $\sim 1.5$ & 60 & 98 \\
\hline 1000 & 299.5 & 296.6 & 2.9 & 299.5 & 1000 & 992 & 8.0 & 31 & $\sim 1.0$ & 50 & 82 \\
\hline 1100 & 302.5 & 300.1 & 2.4 & 302.5 & 1100 & 1093.3 & 6.7 & 25 & $\sim 1.0$ & 40 & 66 \\
\hline 1200 & 305.3 & 303.3 & 2.0 & 305.3 & 1200 & 1194.5 & 5.5 & 22 & $\sim 1.0$ & 35 & 58 \\
\hline 1300 & 308.0 & 306.2 & 1.8 & 308.0 & 1300 & 1295.8 & 4.2 & 18 & $\sim 1.0$ & 30 & 49 \\
\hline 1400 & 312.2 & 310.7 & 1.5 & 312.2 & 1400 & 1396.4 & 3.6 & 16 & $\sim 1.0$ & 25 & 42 \\
\hline 1500 & 315.5 & 314.3 & 1.1 & 315.5 & 1500 & 1497.2 & 2.8 & 12 & $\sim 1.0$ & 19 & 32 \\
\hline 1600 & 320.1 & 319.2 & 0.9 & 320.1 & 1600 & 1598.1 & 1.9 & 8 & $\sim 1.0$ & 14 & 23 \\
\hline 1700 & 324.0 & 323.3 & 0.7 & 324.0 & 1700 & 1698.8 & 1.2 & 6 & $\sim 0.5$ & 10 & 16 \\
\hline 1800 & 328.0 & 327.5 & 0.5 & 328.0 & 1800 & 1799.4 & 0.6 & 4 & $\sim 0.5$ & 6 & 10 \\
\hline 1900 & 333.5 & 333.2 & 0.3 & 333.5 & 1900 & 1899.8 & 0.2 & 2 & 0.5 & 4 & 6 \\
\hline 2000 & 340.5 & 340.4 & 0.1 & 340.5 & 2000 & 1999.9 & 0.1 & 1 & $\sim 0.5$ & 2 & 3 \\
\hline 2100 & 347.0 & 347.0 & 0 & 347.0 & 2100 & 2100 & 0 & 0.5 & 0 & 1 & 1 \\
\hline 2200 & 356.0 & 356.0 & 0 & 356.0 & 2200 & 2200 & 0 & 0 & 0 & 0 & 0 \\
\hline 2300 & 368.0 & 368.0 & 0 & 368.0 & 2300 & 2300 & 0 & 0 & 0 & 0 & 0 \\
\hline
\end{tabular}

From this Table 3 , it is evident that as pressure increases the temperature of freezing $T_{b}$ (or $\left.\alpha_{\min }\right)$ increases and, as the natural result, the other parameters $\left(\Delta \mathrm{T}^{-}, \Delta \mathrm{p}\right.$ and time intervals $\mathrm{t}_{1}, \mathrm{t}_{2}$, $\left.t_{3}, t\right)$ decrease. 


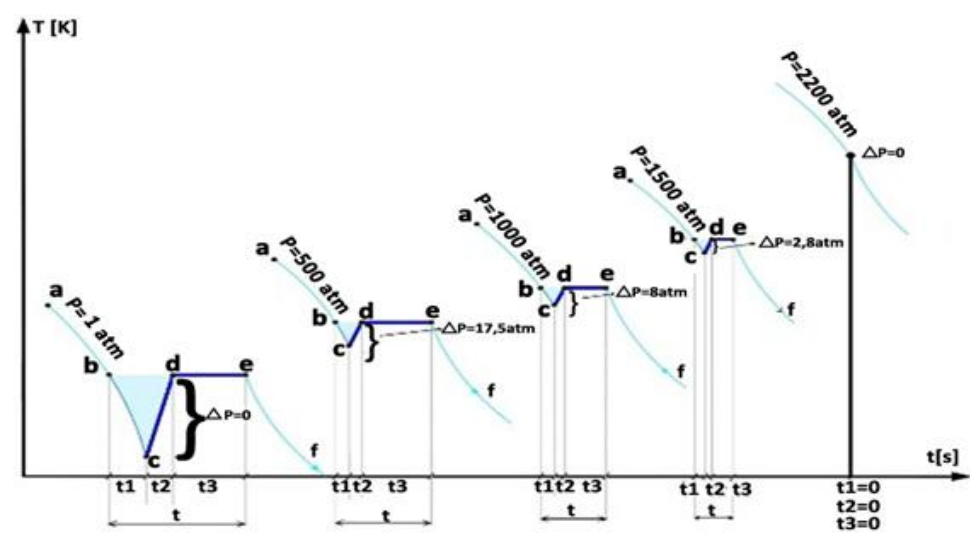

Figure 7. Schematic thermo-grams recorded at pressures $p_{0}=1 ; 500 ; 1000 ; 1500$ and 2200 atm. Freezings $\Delta T^{-}$and pressure differences $\Delta p$ are shown on the boundaries of the metastable state.

To illustrate these changes, in Figure 8 separate thermograms are shown at pressures; $p=1$, $500 ; 1000 ; 1500$; and $2200 \mathrm{~atm}$. On the corresponding points of freezing one can write the equation of dependences:

$$
\begin{gathered}
T_{b}=f(p) ; T_{c}=f(p) ; \Delta T^{-}=f(p) ; \Delta p=f(p) ; t_{1}=f(p) ; t=f(p) \\
T_{b}=A_{1}+B_{1} p+C_{1} p^{2}
\end{gathered}
$$

where $A_{1}=278.5 \mathrm{~K} . B_{1}=7 \cdot 10^{-3} \mathrm{~K} \cdot \mathrm{atm}^{-1} \cdot C_{1}=1.235 \cdot 10^{-5} \mathrm{~K} \cdot \mathrm{atm}^{-2}$

$$
T_{c}=A_{2}+B_{2} p+C_{2} p^{2}
$$

where $A_{2}=258.5 \mathrm{~K} . B_{2}=3.3 \cdot 10^{-2} \mathrm{~K} \cdot \mathrm{atm}^{-1} \cdot C_{2}=4.296 \cdot 10^{-6} \mathrm{~K} \cdot \mathrm{atm}^{-2}$

$$
\begin{aligned}
\Delta T^{-} & =T_{b}(p)-T_{c}(p) \\
\Delta p & =A_{3}-B_{3} p+C_{3} p^{2}
\end{aligned}
$$

where $A_{3}=32$ atm. $B_{3}=3.2 \cdot 10^{-2} . C_{3}=7.794 \cdot 10^{-6} \mathrm{~atm}^{-1}$

$$
t_{1}=A_{4}-B_{4} p+C_{4} p^{2}
$$

where $A_{4}=160$ s. $B_{4}=0.179 \mathrm{~s} \cdot \mathrm{atm}^{-1} \cdot C_{4}=4.980 \cdot 10^{-5} \mathrm{~s}^{-1} \cdot \mathrm{atm}^{-2}$

$$
t=A_{5}-B_{5} p+C_{5} p^{2}
$$

where $A_{5}=426$ s. $B_{5}=0.480 \mathrm{~s} \cdot \mathrm{atm}^{-1} \cdot C_{5}=1.342 \cdot 10^{-4} \mathrm{~s}^{-1} \cdot \mathrm{atm}^{-2}$ 


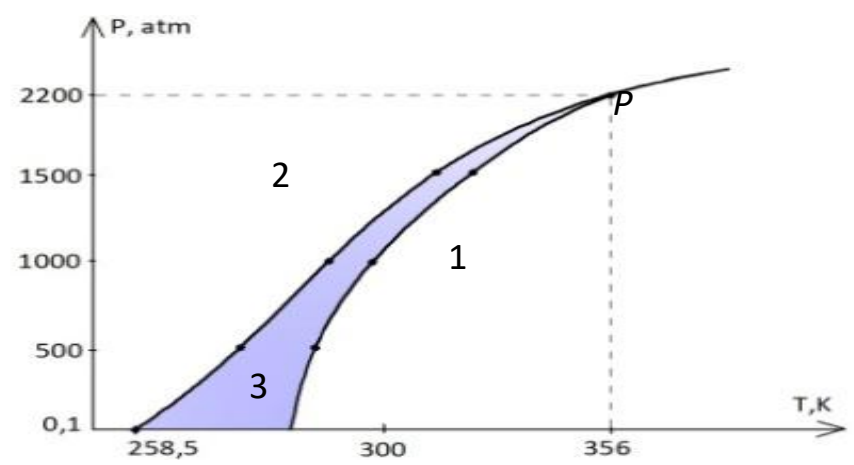

Figure 8. Types of curves: $1-T_{b}=f(p) ; \mathbf{2}-T_{c}=f(p) ; \mathbf{3}-\Delta T^{-}=f(p)$

Relying on these data one can conclude that curves $T_{b}=f(p)$ and $T_{c}=f(p)$ cross at a point $\mathrm{P}$ (Figure 8) at which the meta-stable state parameters $\Delta T^{-}, t_{1}$ and $t$ become equal to zero.

Using the information provided in Table 3, and Figure 7, it was possible to construct a graph similar to Figure 9 in order to determine a limiting value for a pressure beyond which a solid liquid coexistence no longer exists. The value of this pressure is denoted as critical pressure of the liquid $[16,23-30]$. This pressure determines the pressure-dependent boundary range of the liquid phase.

Based on the test results the critical pressure is $p_{c r}=2200$ atm and the corresponding temperature is $\mathrm{T}_{\mathrm{cr}}=356 \mathrm{~K}$ for benzene (Figure 9).

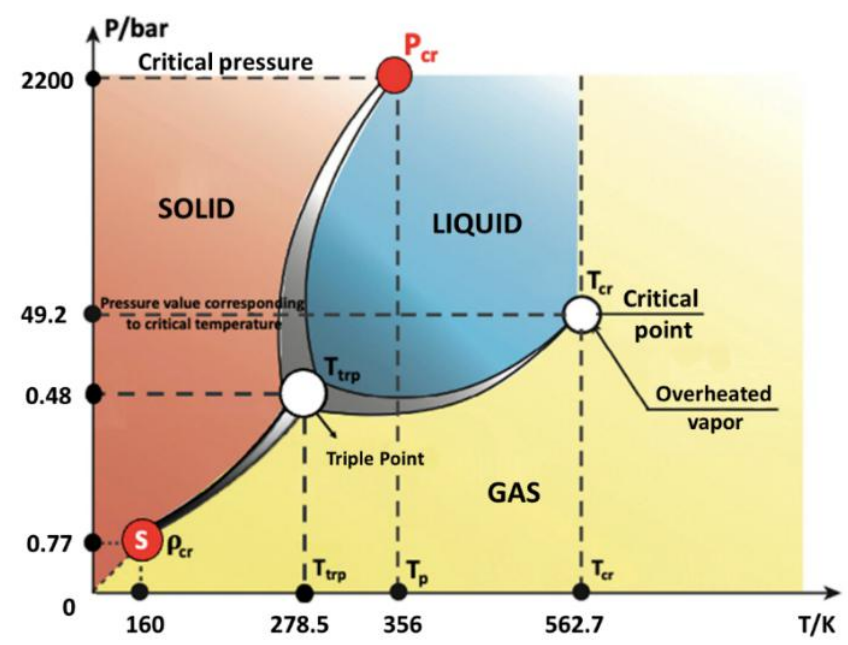

Figure 9. The critical pressure of the liquid phase of benzene is $p_{c r}=2200 \mathrm{~atm}$ and temperature $T=$ 356K 
The results of the graphical method applied to some substances and the experimental results obtained from the metastable state of benzene revealed the presence of critical pressure $p_{\text {cr }}$ on the equilibrium curve and the presence of plasma in the (p-T) phase diagram (Figure 10).

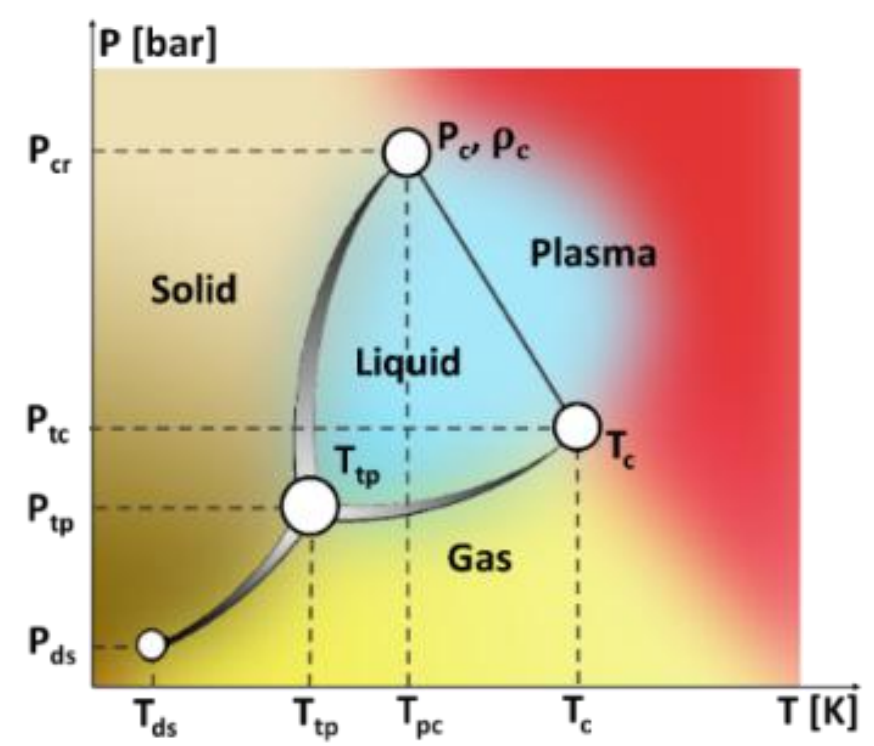

Figure 10. p-T diagram showing the plasma phase

In Figure 10 above, besides the melting, condensation, sublimation equilibrium curves, the ionization equilibrium curve between the two critical points $T_{\mathrm{cr}}$ and $\mathrm{p}_{\mathrm{cr}}$ completes the phase diagram. Gibbs' phase rule determines the phase equilibrium conditions in a system.

Gibbs rule also indicates that there cannot be more than three phases at equilibrium states in a homogeneous system. Although the phase diagram of benzene indicates that four phases (solid, liquid, gas and plasma) coexist, only three phases will always be in equilibrium.

Table 4. Thermodynamic symmetry state of Benzene in p-T diagram

\begin{tabular}{|c|c|c|c|}
\hline Substances & L-S-G $\left(\mathbf{T}_{\text {tp }}\right)$ & L-P-G $\left(\mathbf{T}_{\mathbf{c r}}\right)$ & S-P-L (pr) \\
\hline Benzene & $\mathrm{P}=1 \mathrm{~atm} . \mathrm{T}=278.5 \mathrm{~K}$ & $\mathrm{P}=49.2 \mathrm{~atm} \mathrm{~T}=562.7 \mathrm{~K}$ & $\mathrm{P}=2200 \mathrm{~atm} . \mathrm{T}=356 \mathrm{~K}$ \\
\hline
\end{tabular}

Definition of single component systems with plasma included in phase diagram:

In single component systems the degrees of freedom is only zero.

The number of phases that can be in equilibrium varies from one to four. 


\section{Location of Plasma in The Phase Diagram}

Experimental results and graphs of metastable state liquid benzene at high pressure and temperature were applied to benzene thermodynamic parameters and the existence of a critical pressure $\left(\mathrm{p}_{\mathrm{cr}}\right)$ point on the melting equilibrium curve have been provided. The critical temperature $\left(\mathrm{T}_{\mathrm{cr}}\right)$ point on the evaporation curve and the critical pressure $\left(\mathrm{p}_{\mathrm{cr}}\right)$ points on the melting equilibrium curve determined the location of the plasma $(\mathrm{p}-\mathrm{T})$ in the phase diagram.

In addition, the position of the plasma in the phase diagram formed the ionization equilibrium curve between two critical points $\left(\mathrm{T}_{\mathrm{cr}}\right)$ and $\left(\mathrm{p}_{\mathrm{cr}}\right)$. In this case, the phase diagram consists of melting, evaporation, sublimation and ionization equilibrium curves. Studies on determining the location of plasma in the phase diagram have been carried out for many years and research is still ongoing.

\section{Atomic Model}

A model is a representation of a system in the real world. Models help us to understand systems and their properties. Atom is the smallest unit of any element maintaining its' chemical and physical properties. Different models of the atom have been developed by famous physicists. The concept of another atomic model presented is an attempt to clarify some aspects of the structure of the atom due recent observations and scientific achievements.

\section{Physical and Chemical Properties of Atom}

Each chemical element corresponds to a set of certain atoms.

Physical properties are those that can be observed without changing the identity of the substance. General properties of a substance such as color, density, state of aggregation, melting points, boiling points, $p_{c r}, \rho_{c r}, \mathrm{~T}_{\mathrm{cr}}$ and hardness, etc., are examples of physical properties.

In order to simplify the complexity of the conventional phase diagram, due to atoms inheritance of physicochemical properties of a matter, atomic model is accepted as a model for phase diagram of pure substance. A pressure and temperature-dependent phase diagram of a single component substance has been drawn, provided in Figure 11 a-b. 
a

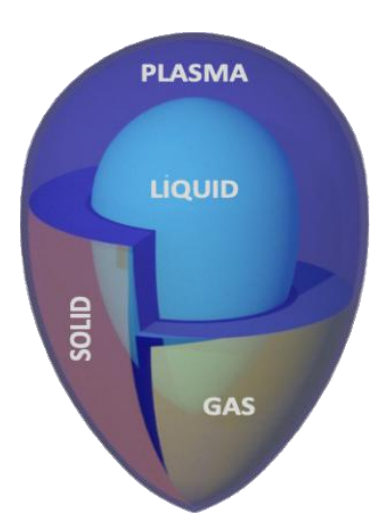

b

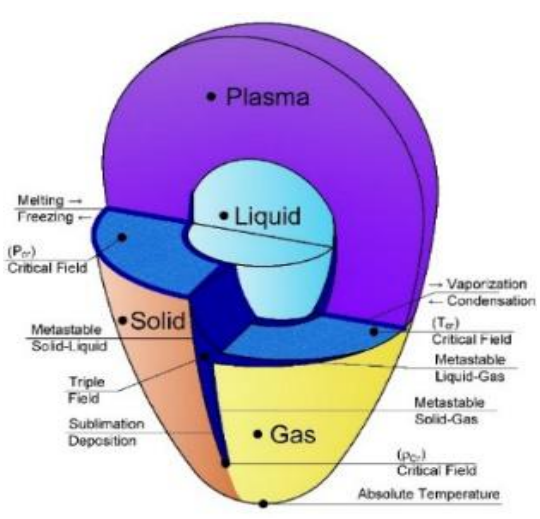

Figure 11 a-b. Thermodynamic surface of matter drawn based on the atomic model

\section{Phase Diagram of Benzene}

Atoms carry the chemical and physical properties of the material, allowing all parameters to take part in the phase diagram of that material. This property of the atom has led to the drawing of the phase diagram of the results we obtained in experimental and graphic studies of benzene.

In order to make the phase diagram of benzene, the atom of benzene (Figure 13) was proposed as a model and a phase diagram was made in the light of the results obtained by graphical and experimental methods.
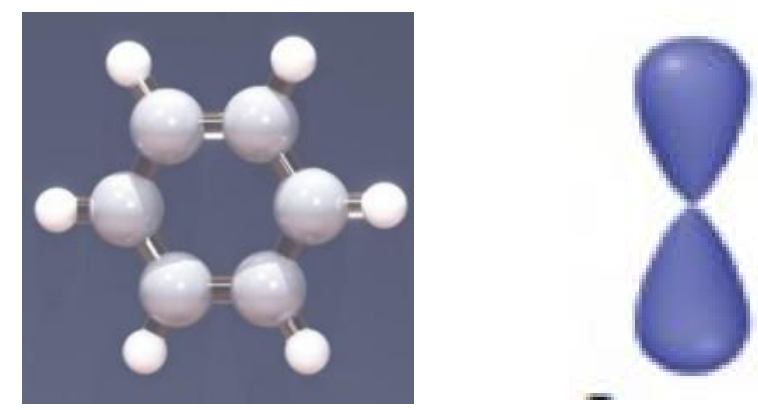

Figure 12. Benzene atom

The phase diagram for benzene provided in Figure 13 containing all four phases(solid, liquid, gas and plasma) but yet, there still only exist three phases at equilibrium conditions $\left(\mathrm{T}_{\mathrm{tp}}, \mathrm{P}_{\mathrm{cr}}\right.$, $\mathrm{T}_{\mathrm{cr}}$ ) where the degree of freedom of the system is equal to zero. The thermodynamic symmetry conditions are provided in Table 4. 


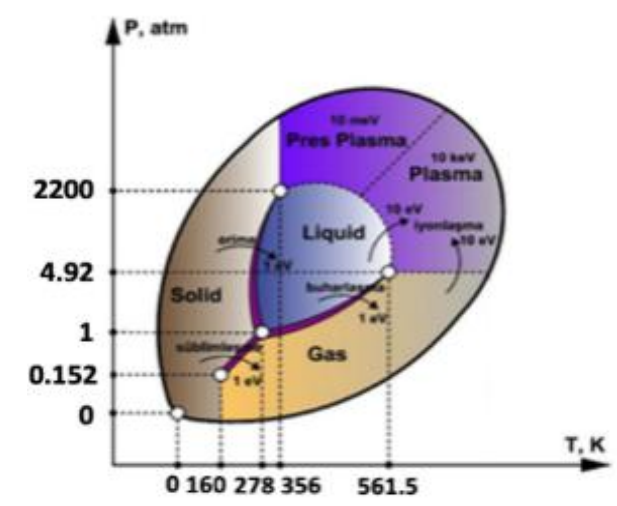

Figure 13. Pressure and temperature (P-T) phase diagram of benzene

\section{Conclusion}

Via applying graphs to thermodynamic parameters, it is possible to determine the equilibrium curves and critical points of all phases and improve the details of the (p-T) phase diagram.

Critical pressure and critical density on the equilibrium curve are determined by applying $(1 / \mathrm{V}-\mathrm{T}) \mathrm{p}=$ constant diagram to the liquid phase of the substances. In addition, the investigation of the metastable state of Benzene at high pressures revealed the critical pressure on the melting equilibrium curve by experiments.

The path followed and basic inferences regarding the determination of plasmas location on the phase diagram are given below.

1. The end point of the melting curve determines the limit range of the liquid phase depending on pressure and temperature.

2. The end point of the melting curve has determined the location of the true critical pressure $\left(\mathrm{P}_{\text {cr }}\right)$.

3. Combining the two critical points $\left(\mathrm{p}_{\mathrm{cr}}, \mathrm{T}_{\mathrm{cr}}\right.$ ) with each other created a new ionization equilibrium curve.

4. The new phase diagram reveals that the degrees of freedom are zero and cannot be changed. (The number of phases that can be in equilibrium is between one and four.)

5. In addition, although there are four phases in the phase diagram, only three phases are in equilibrium.

6. The phase diagram ( $\mathrm{p}-\mathrm{T})$ is drawn by applying the experimental pressure temperature data of Benzene to the atomic model. 


\section{References}

[1] Bedjan İbrahimoğlua;,T. Nejat Veziroğlub , Aydın Huseynovc, Study of thermodynamic parameters of hydrogen gas by grapho-analytic method, International Journal of Hydrogen Energy 30 (2005) 515-519.

[2] B. İbrahimoglu, N. Veziroglu ve A. Hüseynov, Schur, D., (2004), Study of thermodynamic parameters of hydrogen gas by grapho- analytic method. Hydrogen Materials Science and Chemistry of Carbon Nanomaterials, S. 225-232.

[3] Beycan İbrahimoğlu, Çiğdem Kanbeş Dindar, Hazal Erol, Salih Karasarı, Determination of 1/V-T (P, constant) Diagrams of Hydrogen Gases By Graph-Analytical Methods, Journal of Thermal Engineering, Vol. 3, No. 1, pp. 1071-1077, January, 2017, Manuscript Received 29 December.

[4] Beycan Ibrahimoglu, Gözde Tekeli, Zeki Y1lmazoglu, Sinem Yurt, "Investigation of Hydrogen Gas with Graphical Method", 4th International Hydrogen Technologies Congress (IHTEC-2019), Edirne, June 20-23, 2019.

[5] B.I.Farzaliev., A.M.Ragimov, A.T. Hajiyev. Graphical definition of the parameters of the triple equilibrium point. UDC 533.77. "OIL AND GAS" 24. June 1985. Baku, Azerbaijan).

[6] Farzaliev B.I, Aliev N.F., Determination of gases by graphical analytic method. Proceedings of a Scientific Conference Az TU, Baku, 1992. P. 21 (Russian).

[7] Ibrahimoglu B., Grafoanalytical of Critical Pressure in Gas. Finding with the method, vol. 17, 2. Ankara: Journal of Turkish Journal of Science and Technology of Turk; 1994.

[8] Ibrahimoglu B.İ, Ataer O.E., Determination of a Node on the Melting Curve, ULIBTK97,11 th National Congress of Business Science and Technology, Edirne,1997.P.33.

[9] Beycan İbrahimoğlu., Beycan İbrahimoğlu Determination of Liquid Phase Range of Matters by Graphic-Analytical Method. SSRG International Journal of Thermal Engineering (SSRG - IJTE ) Volume 4 Issue 2 May to Aug 2018.

[10] Beycan Ibrahimoglu1, Gozde Tekeli . Application of graphic and graphic-analytic geometry systems on the liquid and gas phases of matter. Научно-технический сборник · ВЕСТИ ГАЗОВОЙ НАУКИ. 163-171. УДК 544.015:514.12.Moskov.

[11] Guseunov S.O., Farzaliev B.I. Naziyev Y.M. The density and dynamic viscosity of benzonitrile at high pressures and temperatures. Known to universities in the USSR."OIL and GAS" 1978.12.pages 48. 
[12] Guseunov S.O.,Farzaliev B.I. Naziyev Y.M. Investigation of dynamic viscosity of OMethylanil at high pressure and temperature..Known to universities in the USSR. "OIL and GAS" 1979.7. pages 52.

[13] Guseinov S.O., Farzaliev B.I. Investigation of the density and dynamic viscosity of a Ptoloudine under high pressures and temperatures.Known universities in the USSR."Oil and Gas" 1981 6.p.65-68.

[14] Naziyev Y.M.Guseynov S.O. und B.İ.Farzaliev. Untersuchungen zur Dichte und dynamischen viskositat dev o-m und p-toluidine bei hohen Drücken und verschiedenen temperaturen. Chemische technik 35Jg. hefr 1.Januar 1983.s.-40 42.

[15] Григорьев Б. А. Теплофизические свойства углеводородов нефти, газовых конденсатов, природного и сопутствующих газов: в 2 т. / Б.А. Григорьев, А.А. Герасимов, И.С. Александров; под общ. ред. Б.А. Григорьева. - М.: Издательский дом МЭИ, 2019. Т. 1. - 735с.

[16] Mustapha Azreg-A“inou, Beycan Ibrahimoglu. High-pressure effects on the benzene precrystallizationmetastable states.

[17] İbrahimoğlu B., Karakaya F., Gasimova T., 'Super Phase Transition and Super Metastable State', Chemical Physics, 2021, https://doi.org/10.1016/j.chemphys.2021.111318

[18] V. D. Alexandrov, B.Ibrahimoğlu, A. E. Pokintelitsa, Pressure Falling Effects Accompanying Phase Transitions of Benzene Under The Accesion of Comprehensive Compression 541.64: 542.62: 546.23 Modern Building Materials Edition 20151 (111) Ukraina

[19] B.Ibrahimogly, Chidem Kanbesh, I.M.Ahmedov PHASE TRANSFORMATIONS OF BENZENE IN TERMS OF LOW TEMPERATUES AND HIGH PRESSURES23, Chemistry Problems N4-2015,p 367-371 UDK-541,64; 546-13. Baku Azerbaijan

[20] Farzaliev B. I, Aliev N. F On benzene phase transitions at high pressures // Thermodynamic and transport properties. substances. Themed. Science. Work. - Baku, LzPy, 1989. - pp.61-65.

[21] S. Glasstone. (1948) Theoretical Chemistry. Boston College. New York. 632 p..

[22] Benzen // Encyclopaedic Dictionary of Brockhaus and Ephron: 86 vols.- St.Pb, 18901907. [25] L. Ciabini. F.A. Gorelli. M. Santoro. R. Bini. V. Schettino. and M. Mezouar. (2005).Phys. Rev. B 72. 094108-1 .

[23] P.G. Debcnedetli. (1996) Metastable Liquids: Concepts and Principles (Priceton University Press. Priceton. NJ.). 
[24] M. Azreg-Aïnou. A. Hüseynov. B. Ibrahimoğlu. (2006).Phase equilibrium and metastability of liquid benzene at high pressures // J. of Chemical Physics. 124. 204505.

[25] Crystal Growth of Electronic Materials, edited by E. Kaldis _North-Holland, Amsterdam, 1985. [29] B. İbrahimoğlu, Y. M. Naziyev, and N. F. Aliyev, Contribution to the Scientific and Technical Congress on Heat Processes, Baku, Azerbaijan, 1992 unpublished.

[26] V.D.Alexandrov. (2011) Kinetics of Nucleation and Mass Crystallization of an Overcooled Liquid and Amorphous Media. - Donetsk: Donbas - 592 p.

[27] V.D.Alexandrov, V.A.Postnikov. (2004) Investigation of overcoolings in benzene crystallization // Ukr. Chem.J., Vol. 70, No. 10. - P. 98-103.

[28] M. Azreg-Aïnou. A. Hüseynov. B. Ibrahimoğlu. (2006).Phase equilibrium and metastability of liquid benzene at high pressures // J. of Chemical Physics. 124. 204505.

[29] P.W. Bridgman. (1964). Collected Experimental Papers. Harvard University Press, Cambridge, Massachusetts.

[30] V.P. Skripov. (2002). The concept of metastability and phase transitions. Thermophysical properties of matter. No.10 